\section{RUBBER SINK STOPPER AND OVERFLOW DRAIN FOR ROENTGEN-RAY DARK ROOM}

Jack Withierspoon, M.D., NAshville, Tenn.

Physicians who are engaged in Rocntgen-ray work, and especially those who develop their own plates and films, will appreciate this contrivance to do away with the pan for
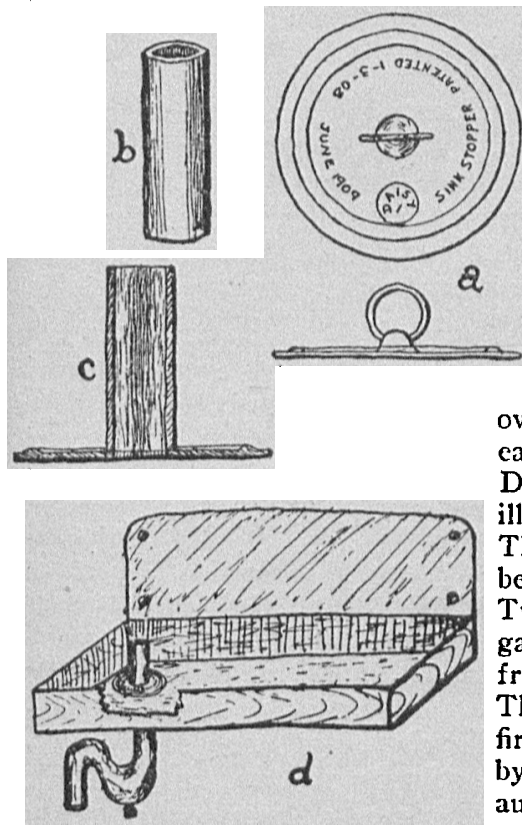

Rubber sink stopper and overflow drain; $a$, stopper; $b$, tube; $c$, tube vul

a canized to stopper and ring cut out; $d$ sink with contrivance in position. washing plates. The ordinary No. 3 sink will accommodate 14 by 17 plates, chest plates, and two or more 8 by 10 or smaller plates, and this size sink should be in the dark room. It should be enameled for purposes of casy cleaning.

The contrivance is a rubber sink stopper and overflow drain cheaply and casily made. A 10 cent Daisy sink stopper, as illustrated, is purchased, This is a flat disk of rubber $4 \frac{1}{2}$ inches in diameter. Two inches of stiff rubber garden hose are obtained from the hardware dealer. The tube is vulcanized firmly on the sink stopper by the man who repairs automobile tires. The ring under the tube is cut out. One now has an overfiow sink stopper which will adhere to the strainer of the sink by suction, and will keep 2 inches of running water in the sink.

216 Doctors' Office Building.

\section{A MODIFIED BIFOCAL LENS}

\section{Arthur J. Hill, M.D., Canton, Ohro}

The ordinary bifocal lens is of no use to the presbyope

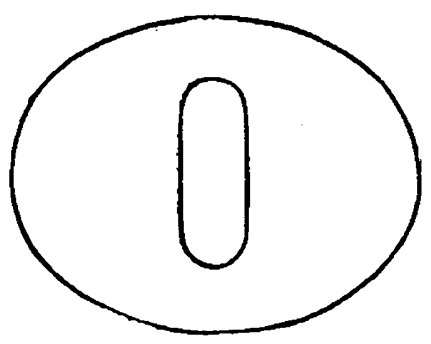

Modified bifocal lens. who uses a headmirror or headlight. If he will have a 12 by $24 \mathrm{~mm}$. segment of the proper strength cemented vertically on the center of his distance correction (as in illustration), he will have all the advantages of his near correction and be able to see at a distance by simply turning his head to one side or the other and looking in the opposite direction.

\section{A SIMPLE INCUBATOR}

Arthur Julius Skeel, M.D., Cleveland

Fellow of the American College of Surgeons; Associate Clinical Professor of Obstetrics, Western Reserve University, School of Medicine; Obstetrician, St. Luke's Hospital

The success which we have had with an inexpensive and simple incubator, whch I devised for our use at St. Luke's, together with a number of requests from physicians, leads me to publish this description. The incubator as presented provides equable safe heat, adequate moisture, and a constant supply of circulating air. With ordinarily intelligent supervision it is absolutely safe.

On two points in its management emphasis must be placed:

1. The electric light bulbs must be shaded to protect the infant's eyes from the light.
2. The incubator must be kept at a higher temperature than that of the room air to insure circulation.

It consists of a large box with an air inlet opening near the base at one end, and a similar air outlet near the top at the other end. The heat is supplied by a row of electric lights (other heat units may be used, but light bulbs are always available) located at the air inlet; the heated air rises, passes over the child, and escapes at the upper or air

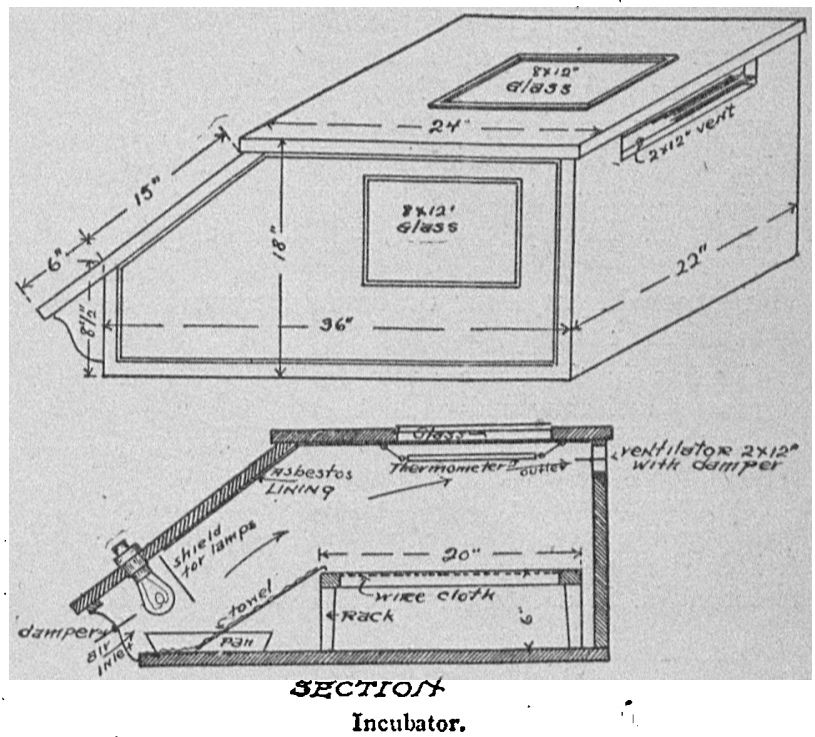

outlet opening. This provides a constant current of warmed air. The air is moistened before it reaches the baby by means of a towel placed on a slanting rack. The lower end of this towel is in a pan of water on the floor of the incubator, and capillarity keeps the entire towel moist. The rising heated air strikes this wet surface and takes up moisture.

To guard against accident, we lined the wooden box with sheet asbestos. This also renclers the box easy to heat. Glass panes in the sides and on the licl expose to view the baby, and a thermometer by which the temperature is regu. lated. The air inlet and outlet are provided with a slide or clamper by means of which the size of the openings may be regulated.

The exact temperature at which the incubator is kept may easily be regulated by the number of lights kept burning.

\section{AN INSTRUMENT TO AID RETROGRADE SÖUNDING OF URETHRA}

\section{J. L. Stevens, M.D., Mansfield, OHio}

This is an olive-tipped bougie, the curved part of which is a steel spring, which allows it to straighten during passage

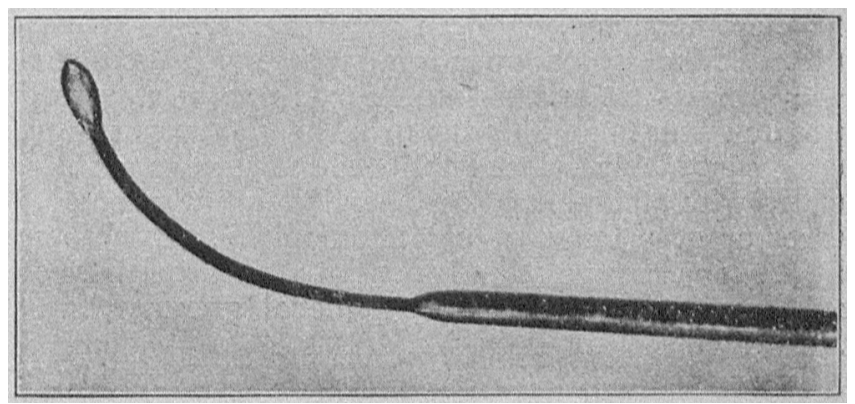

through a straight cannula. The bladder should contain 150 c.c. or more of fluid. A trocar and cannula are inserted into it above the pubes in the usual way, and the trocar is replaced by the bougie without allowing the fluid to escane. If the full curve is not desired in searching for the urethra, the spring part should not be entirely passed through the cannula. After the entrance to the urethra is found, the flexibility of the spring will allow the tip to follow the urethra. 